\title{
A pathological role for damaged hyaluronan in synovitis
}

\author{
E B Henderson, M Grootveld, A Farrell, E C Smith, P W Thompson, D R Blake
}

Hyaluronan (hyaluronic acid, hyaluronate, see ref 1 for discussion of current nomenclature) is a linear repeating disaccharide, $\beta$-D-glucuronyl$\beta$-D- $N$-acetylglucosamine, of high molecular weight (upwards of 10000000 daltons). It is almost ubiquitous in its distribution, being present in the interstitial spaces on most animal tissues. ${ }^{2}$ Hyaluronan also forms the central axis of the proteoglycan aggregates necessary for the functional integrity of articular cartilage and other extracellular matrices. ${ }^{3}$

In its unaggregated form hyaluronan is secreted continuously into the joint space by elements of the synovium, though some contribution may be made by the chondrocyte. ${ }^{4}$ It comprises the major macromolecular species of the synovial fluid and is responsible for the unique viscoelastic properties of what is otherwise effectively a simple plasma dialysate. The secondary structure of the glycosaminoglycan chain consists of a fairly stiff helical ribbon stabilised by four internal hydrogen bonds per disaccharide unit. These lie parallel to the axis of the ribbon, and are supplemented by water bridges such that the molecule may take up the tertiary structure of a random coil in an aqueous environment at physiological $\mathrm{pH} .{ }^{5}$ A fully hydrated molecule of hyaluronan of $M_{r}=4$ megadaltons would comprise a chain of 10000 disaccharide units and occupy a spherical domain with a diameter of about 0.5 microns. At a concentration of $1 \mathrm{mg} / \mathrm{ml}$ these domains would just touch each other with the virtual exclusion of all interdomain solvent. At concentrations greater than $1 \mathrm{mg} / \mathrm{ml}$ the domains overlap and intermingle forming a continuous three dimensional network solution with nonlinear viscoelastic properties. ${ }^{6-8}$ This is the situation within normal synovial fluid where hyaluronan of $M_{r}=1 \cdot 6-10.9$ megadaltons is found at concentrations ranging from 1.45 to $3 \cdot 12 \mathrm{mg} / \mathrm{ml}$. 910

Hyaluronan is normally present in the serum

The Inflammation Group, Bone and Joint Research Unit, The London

Hospital Medical College, 25-29 Ashfield

Street, London E1 2AD E B Henderson M Grootveld

A Farrell

E C Smith

P W Thompson

D R Blake

Correspondence to:

Professor Blake. in small amounts, of the order of 10-100 $\mu \mathrm{g} / 1 .^{11}$ Hyaluronan concentrations are raised up to sevenfold, however, in the sera of patients with rheumatoid arthritis and other inflammatory arthritides. ${ }^{12} 13$ Engstrom-Laurent and Hallgren have found early morning rises of serum hyaluronan in both patients and healthy controls, implying a relation with exercise and the movement of inflamed joints. ${ }^{14}$ These authors speculate that increased hyaluronan production and its intra-articular accumulation during overnight rest might in part account for the phenomenon of morning stiffness.

\section{Hyaluronan and synovitis}

In rheumatoid arthritis and other inflammatory arthritides synovial hyaluronan is fragmented and depolymerised with a corresponding reduction in synovial fluid viscosity. This leads to an increase in the synovial concentration of dialysable hyaluronan fragments and saccharide monomers. There is broad agreement among a number of studies showing an increase in the total amount, but a decrease in the concentration $(1.09-1.20 \mathrm{mg} / \mathrm{ml}$, probably a dilutional effect) and in the average molecular weight $(1 \cdot 2-4 \cdot 5$ megadaltons, data from ref 10$)$ of hyaluronan in rheumatoid synovial fluids. ${ }^{10} 1516$

The apparent decrease in the weight average molecular mass of synovial hyaluronan in these patients may be explained in two ways: either by defective synthesis with premature termination of the nascent polysaccharide chain, or by fragmentation of the intact chain after secretion into the synovial cavity. Recent pulsechase experiments have supported the view that the presence of short chain molecules of hyaluronan in arthritic synovial fluid is due to degradation after synthesis rather than to defective synthesis. ${ }^{17}$ As normal and inflammatory synovial fluids contain no hyaluronidase activity it has been inferred for some time that reactive oxygen derived radical species (RORS) cause hyaluronan depolymerisation. ${ }^{18-20}$ Broadly, the evidence derives from two approaches: $(a)$ the demonstration of potential free radical generating systems within the joint and $(b)$ the demonstration of hyaluronan degradation by such systems in vitro as shown by decreased viscometric parameters and apparent hyaluronan molecular mass when measured by gel filtration.

\section{Free radicals and synovitis}

There is an increasing body of evidence, both direct and indirect, implicating RORS in the generation and perpetuation of inflammation. ${ }^{21-25}$ Recent studies have shown the presence of systems prerequisite to the formation of such free radicals within the synovial membrane of the inflamed joint. ${ }^{2627}$. Other studies have shown several products of free radical attack upon biological molecules and 
intracellular structures within the inflamed joint. ${ }^{28-31}$

The generation of RORS, however, requires oxygen. The oxygen tension of inflammatory synovial fluid is low; Lund-Oleson reported a mean synovial $\mathrm{Po}_{2}$ of $26 \mathrm{mmHg}$ in 85 patients with rheumatoid arthritis. ${ }^{32}$ Edwards et al found that the ability of stimulated rat neutrophils to produce RORS was in part dependent on the ambient $\mathrm{O}_{2}$ concentration. ${ }^{33}$ The apparent paradox of finding RORS mediated damage in a relatively hypoxic environment may be resolved by considering the mechanism of hypoxia/reperfusion injury.

Active synovitis is associated with increased synovial oxygen demand, especially during the proliferative phase, and with a corresponding increase in blood flow. ${ }^{34}$ Synovial oxygen tension is critically dependent, therefore, upon the maintenance of an adequate synovial blood flow. Jayson and Dixon showed that the normal human joint has a subatmospheric pressure at rest, which remains subatmospheric during exercise, whereas inflamed joints have resting intra-articular pressures above one atmosphere, which rise to exceed the local capillary perfusion pressure when exercised. ${ }^{35}$ With hydrostatic closure of the superficial capillary bed during movement of the inflamed joint, the supervening ischaemic hypoxia sets in motion a series of biochemical events which uncouple some intracellular redox systems leaving elements of the synovial tissue poised to generate potentially damaging RORS immediately on the reintroduction of oxygen. When joint movement stops the intra-articular pressure falls, allowing reopening of the capillary bed. With the restoration of synovial blood flow and oxygen delivery various RORS may be generated, including the highly reactive hydroxyl $\left({ }^{\bullet} \mathrm{OH}\right)$ radical by way of the Fenton reaction.

$$
\mathrm{H}_{2} \mathrm{O}_{2}+\mathrm{Fe}^{2+} \rightarrow{ }^{\bullet} \mathrm{OH}+\mathrm{OH}^{-}+\mathrm{Fe}^{3+}
$$

Details of these mechanisms and the evidence for their involvement in synovitis are reviewed elsewhere. ${ }^{232436}$ The ${ }^{\circ} \mathrm{OH}$ radical can attack a wide range of biomolecules, including lipids, proteins, and polysaccharides.

In 1986 we suggested that fluxes of oxygen derived free radicals and other reactive oxygen species are generated by means of continuous hypoxia/reperfusion cycles within the inflamed joint during movement associated with routine daily activity, and that these fluxes are responsible for damage to joint microvasculature and parenchymal structures. Such reperfusion cycle-driven fluxes would be inevitable in the ambulatory patient, and would thereby perpetuate the inflammatory state. ${ }^{37}$ This may explain the dogged persistence of chronic synovitis, and the well known, albeit transient, therapeutic benefit of bed rest and joint splintage. It might be further supposed that with accumulated damage over a period of time the reperfusion potential of the microvasculature would progressively decline. This might offer an explanation as to why some cases of rheumatoid arthritis ultimately and spontaneously 'burn out'.

\section{Free radicals and hyaluronan}

It has been shown by $\gamma$ radiolysis that hyaluronan is susceptible to hydroxyl radical attack. ${ }^{18} 19$ We have presented elsewhere direct evidence for RORS mediated damage to hyaluronan in the synovial fluid and serum of patients with inflammatory joint disorders. ${ }^{38}$ Methods using high resolution, high field proton Hahn spin-echo Fourier transform nuclear magnetic resonance spectroscopy (SEFT-NMR) have been developed to study oxidative damage to hyaluronan in vitro by RORS generated by $\gamma$ irradiation and to characterise the end products. This powerful technique has the advantage of allowing a detailed analysis of small molecules suspended in complex biological fluids with minimal manipulation of the sample. SEFTNMR has also been used to study oxidative damage to synovial fluid hyaluronan in vivo by RORS generated during hypoxic/reperfusion injury, and to detect the end products of RORS mediated hyaluronan degradation both in the synovial fluid and in the serum of patients with inflammatory joint disease.

The first of these studies ${ }^{38}$ showed that free radical attack on pure hyaluronan in vitro results in the formation of metabolites, including formate and very low molecular weight $\left(M_{\mathrm{r}}=\right.$ ca 1000$)$ oligosaccharides containing $N$ acetylglucosamine. This would correspond to a fragment containing two disaccharide units of a hyaluronan chain. These species have also been detected by SEFT-NMR in the synovial fluid from patients with inflammatory joint diseases but not from normal or non-inflammatory controls. Both these species, however, were seen in the non-inflammatory synovial fluids after $\gamma$ radiolysis. $\gamma$ Irradiation (which generates - $\mathrm{OH}$ radicals from water) of normal serum results in the generation of formate resonances only. These presumably derive from glycoproteins and other non-hyaluronan carbohydrate systems present in the serum. No oligosaccharide resonances were seen (normal serum contains only tiny amounts of hyaluronan), suggesting that the saccharide moieties of glycoproteins are not the substrate for its appearance in the patients' synovial fluid.

These studies were extended to the hypoxia/ reperfusion model ${ }^{39}$ (more fully described in ref 40), and 20 patients with rheumatoid arthritis with clinically evident knee effusions were exercised either by isometric quadriceps contraction or by walking up stairs for two minutes. Serial synovial fluid samples were aspirated after exercise every two minutes until the knee was dry. In 15 of the patients analysis of these spectra showed an induction or increase in intensity after exercise of a resonance attributable to a low molecular mass oligosaccharide (figure) identical with that seen in the previous series. The intensity of this resonance was maximal at four minutes after exercise. The spectra also indicated an increase in formate concentrations after exercise consistent with -OH radical attack on synovial carbohydrate systems, including hyaluronan.

We interpret these data to support the hypothesis that oxygen free radicals generated by exercise-induced hypoxia/reperfusion cycles 

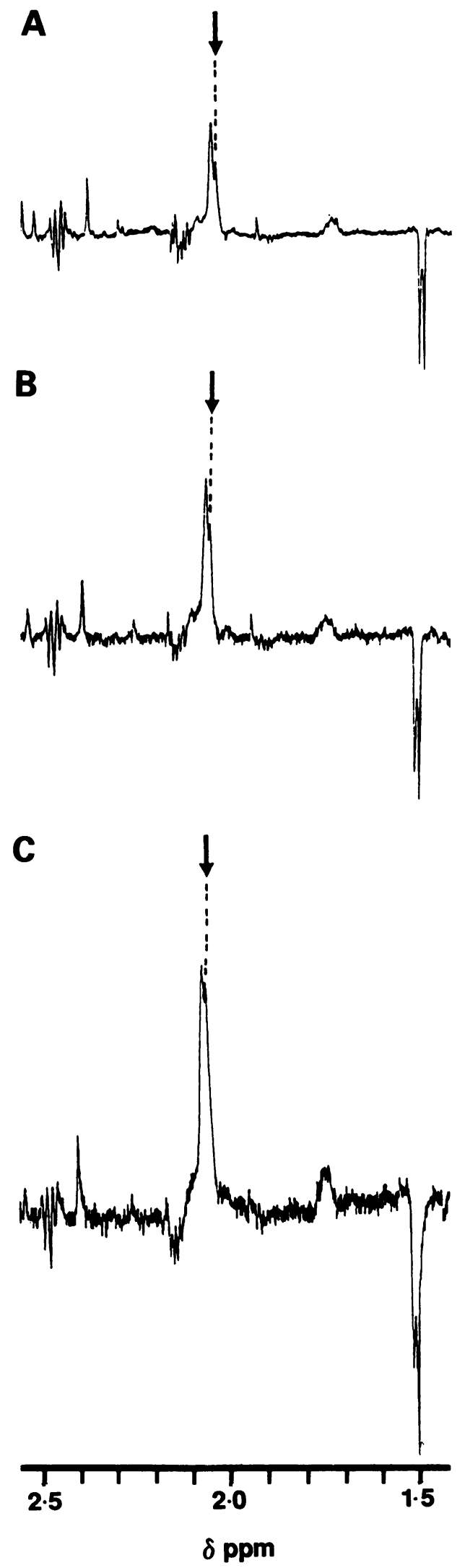

Proton Hahn spin-echo Fourier transform nuclear magnetic resonance spectra of a rheumatoid effusion aspirated from the knee of a rested patient: $(A)$ immediately before a standardised two minute period of exercise; $(B)$ immediately standardised two minute period of exercise; $(B)$ immediate oligosaccharide peak (arrowed on the descending shoulder of a larger peak located slightly downfield) at $2 \cdot 044 \mathrm{ppm}$ is clearly seen to rise after exercise of the inflamed joint, reaching a maximum at four minutes after exercise. Nuclear magnetic resonance measurements on these samples were performed on a fOEL $\mathcal{F} N M-G S X$ spectrometer operating in quadrature mode at $500 \mathrm{MHz}$. degrade synovial hyaluronan in inflamed joints. We suggest that these free radical damaged species derived from the joint may provide a sensitive index of disease severity, and possibly indicate those at risk in subclinical disease.

Hyaluronan, some biological considerations Hyaluronan is far from an inert space filler or static scaffolding for other extracellular matrix molecules. It is thought to have an important role in biological activities as diverse as cellular motility, cell-cell interaction, development and differentiation, cell-matrix adhesion, and the ordering of the extracellular matrix. ${ }^{41}$

Cells from a variety of tissues have been shown to bear fairly specific high affinity hyaluronan receptors at their surfaces. ${ }^{42} 43$ The hyaluronan receptor is a transmembrane glycoprotein of $M_{r} 85000,{ }^{44}$ whose intracellular face seems to interact with the actin filaments of the cytoskeleton. ${ }^{45}$ Clustering of these receptors by cooperative binding to hexasaccharide sequences of a single high molecular weight molecule of hyaluronan may have far reaching effects on the cell's behaviour and interaction with its environment. Bound hyaluronan molecules may provide a physical barrier at the cell surface both to cell-cell communication and to cellsubstrate adhesion. By controlling the dispersal of hyaluronan receptors through elements of the cytoskeleton, the cell may be able to vary its adhesive properties and even membrane fluidity at different parts of its surface. It may even use such a mechanism to modulate its sensitivity to chemical messengers such as hormones or chemotactic gradients. The receptor also binds chondroitin sulphate, albeit much less avidly. ${ }^{46}$ This differential binding may provide further environmental information to the cell, which might be important in directing cell migration.

Subsets of inflammatory cell populations bear cell-surface hyaluronan receptors. ${ }^{47}$ It is not unreasonable to suppose that some of their activities may be determined, or at least influenced, by the hyaluronan status of their immediate environment. Several studies have suggested that high molecular mass hyaluronan inhibits cellular proliferation of endothelial cells, ${ }^{48}$ fibrocytes, ${ }^{49}$ and mitogen stimulated lymphocytes, ${ }^{50}$ whereas low molecular mass fragments have the converse effect. High molecular mass hyaluronan has been shown to inhibit phagocytosis, with low molecular mass fragments having a stimulatory effect. ${ }^{51} 52$ Low molecular mass fragments have been shown to stimulate angiogenesis, an important feature of early inflammation. ${ }^{53}$ Synovial production of inflammatory mediators, such as prostaglandin $E_{2}$, has been shown to be reduced by the administration of exogenous hyaluronan in a molecular mass dependent manner comparable with the oral administration of non-steroidal anti-inflammatory drugs. ${ }^{54}$

\section{Speculations}

We believe that the effects of free radical mediated damage to hyaluronan within the joint extend beyond the rheological consequences of 
reduced synovial fluid viscosity. We suggest that at least some of the products of synovial hyaluronan breakdown may not only be induced by, but subsequently contribute to, the cyclical hypoxia/reperfusion injury of synovitis. Damaged hyaluronan would thereby constitute the substrate of a positive feedback loop, promoting perpetuation of the inflammatory state.

The very low molecular mass hyaluronan fragments which we have identified might compete with native hyaluronan for the hexasaccharide recognition sites on the hyaluronan receptor or perhaps alter their binding constants, thus intefering with receptor clustering and cellular behaviour. Fragment polarity as well as size may be important here.

Formate is toxic in its own right, being the principal active metabolite of methanol poisoning. ${ }^{55}$ It contributes substantially to the metabolic acidosis associated with this condition in humans. ${ }^{56}$ It is also known to inhibit mitochondrial respiration in vitro, which may be responsible for its occular toxicity. ${ }^{57}$ The development of animal models for the demonstration of a putative participation of formate in inflammation is hampered by species differences in formate handling.

\section{Conclusions}

Native hyaluronan is an important structural and dynamic element crucial to the functioning of the normal synovial joint. Fragmentation of the molecule would be expected to disrupt the network lattice of synovial hyaluronan with deleterious mechanical consequences to the joint. We further contend that low molecular weight products of free radical mediated hyaluronan degradation, such as formate and oligosaccharides less than three disaccharide units in length, may, quite apart from expressing any proinflammatory potential of their own, interfere with normal hyaluronan-cell and hyaluronan-matrix relationships, aggravating and contributing to the perpetuation of synovitis.

Over the past 15 years a number of clinical trials of several different preparations of intraarticularly administered hyaluronan in the treatment of arthritic conditions have been undertaken. ${ }^{58-65}$ Although methodological variations make direct comparisons difficult, there is a broad consensus that this treatment reduces the pain of osteoarthritis. Some studies indicate that this effect may be long lived, lasting six months or more, implying that 'normalising' the intraarticular environment may stimulate the hyaluronan secreting cells. Although side effects are uncommon, several studies report a cohort of patients who experience a transient increase in pain and swelling in the treated knee, usually lasting for no more than a few days.

We suggest that viscosupplementation with exogenous hyaluronan of specified molecular weight to promote the secretion by the synovium of intact native hyaluronan, thereby restoring the normal hyaluronan status of the joint, is only half the story. In the face of continuing hyaluronan degradation within the joint this has the effect of simply providing further substrate for the generation of potentially damaging end products, and therefore the procedure eventually becomes self defeating. This may explain the side effect of an acute transient synovitis seen in some patients. To be effective viscosupplementation must be combined with a strategy to prevent the intrasynovial degradation of hyaluronan itself.

1 Balazs E A, Laurent T C, Jeanloz R W. Nomenclature of hyaluronic acid. Biochem $\mathcal{f}$ 1986; 235: 903.

2 Laurent T C, Fraser L I. The properties and turnover of hyaluronan. In: Evered D, Whelan J, eds. Functions of the hyaluronan. In: Evered D, Whelan J, eds. Functions of the proteoglycans. Chichester: Wiley,

3 Hardingham T E, Muir H M. The specific interaction of hyaluronic acid with cartilage proteoglycans. Biochim Biophys Acta 1972; 279: 401-5.

$4 \mathrm{Ng} \mathrm{C} \mathrm{K}$, Handley C J, Mason R M, Robinson H C. Synthesis of hyaluronate in cultured bovine articular cartilage. Biochem $\mathcal{F}$ 1980; 263: 761-7.

5 Scott J E. Secondary structures in hyaluronan solutions: chemical and biological implications. In: Evered D, Whelan J, eds. The biology of hyaluronan. Chichester: Wiley, 1989: 6-20.

6 Gibbs D A, Merrill E W, Smith K A, Balazs E A. Rheology of hyaluronic acid. Biopolymers 1968; 6: 777-91.

7 Balazs E A, Gibbs D A. The rheological properties and biological function of hyaluronic acid. In: Balazs E A, ed. biological unction or hyauronic acid. In. Balazs E A, ed. Chemistry and molecular biology of the intercellular matrix.

8 Bothner H, Wik O. Rheology of hyaluronate. Acta Otolaryngol Suppl (Stockh) 1987; 442: 25-30.

9 Sundblad L. Glycosaminoglycans and glycoproteins in synovial fluid. In: Balazs $\mathrm{E} A$, Jeanloz $\mathrm{R} W$, eds. The amino sugars. Vol IIA. New York: Academic Press, 1965: 229-50.

10 Balazs E A, Watson D, Duff I F, Roseman S. Hyaluronic acid in synovial fluid. Molecular parameters of hyaluronic acid in normal and arthritic fluids. Arthritis Rheum 1967; 10: 357-76.

11 Engstrom-Laurent A, Laurent U B G, Lilja K, Laurent T C. Concentration of sodium hyaluronate in serum. Scandinavian Foumal of Laboratory Investigation 1985; 45

Engstrom-Laurent A, Hallgren R. Circulating hyaluronate in rheumatoid arthritis: relationship to inflammatory activity rheumatoid arthritis: relationship to inflammatory activity and the effect

13 Horslev-Petersen K, Bentsen K D, Engstrom-Laurent A Junker $P$, Halberg $P$, Lorenzen I. Serum aminotermina type III procollagen peptide and serum hyaluronan in rheumatoid arthritis: relation to clinical and serological parameters of inflammation during 8 and 24 months treatment with levamisole, penicillamine, or azathioprine. Ann Rheum Dis 1988; 47: 116-26.

14 Engstrom-Laurent A, Hallgren R. Circulating hyaluronic acid levels vary with physical activity in healthy subjects and in rheumatoid arthritis patients. Arthritis Rheum 1987 30: $1333-8$.

15 Balazs E A. The physical properties of synovial fluid and the special role of hyaluronic acid. In: Helfet J, ed. Disorders of

16 Dahl L B, Dahl I M S, Engstrom-Laurent A, Granath K. Concentration and molecular weight of sodium hyaluronate in synovial fluid from patients with rheumatoid arthritis in synovial fluid from patients with rheumatoid arthritis

17 Prehm P. Release of hyaluronate from eukaryotic cells. Biochem f 1990; 267: 185-9.

18 Phillips G O, Filby W G, Moore J S, Davies J V. Radiation studies of aryl glycosides: I-III. Carbohydr Res 1971; 16: 79-111.

19 Greenwald R A, Moy W W. Effect of oxygen derived free radicals on hyaluronic acid. Arthritis Rheum 1980; 23: 255-63.

20 NcNeil J D, Weibkin O W, Betts W H, Cleland L G. Depolymerisation products of hyaluronic acid after exposure to oxygen derived free radicals. Ann Rheum Dis 1985; 44: 780-9.

21 McCord J M. Oxygen-derived free radicals in postischemic tissue injury. N Engl f Med 1985; 312: 159-63.

22 Halliwell B. Oxidants and human disease: some new concepts. FASEB F 1987; 1: 358-74.

23 Blake D R, Allen R E, Lunec J. Free radicals in biological systems: a review orientated to inflammatory processes. $B$ Mystems: a review orientated

24 Lunec J, Blake D. Oxidative damage and its relevance to inflammatory joint disease. In: Ching Quang Chow, ed. Critical reviews in chemistry: cellular antioxidant defence mechanisms. Vol III. Boca Raton, Florida, USA: CRC Press, 1988: 143-59.

25 Henderson E, Grootveld M, Blake D. Origins of free radicalmediated damage in the inflamed joint. Eur $\mathcal{F}$ Rheumatol Inflamm (in press).

26 Morris C J, Blake D R, Wainwright A C, Stevens M M. The relationship between iron deposits and tissue damage in the synovium: an ultrastructural study. Ann Rheum Dis 1986; 
27 Allen R E, Outhwaite J M, Morris C J, Blake D R. Xanthine oxidoreductase is present in human synovium. Ann Rheum Dis 1987; 46: 843-5.

28 Rowley D A, Gutteridge J M C, Blake D R, Farr M, Halliwell B. Lipid peroxidation in rheumatoid arthritis: thiobarbituric acid-reactive material and catalytic iron salts in synovial fluid from rheumatoid patients. Clin Sci 1984; 66: 691-5.

29 Wong P S, Travis J. Isolation and properties of oxidised alpha-1-proteinase inhibitor from human rheumatoid alpha-1-proteinase inhibitor from human rheumatoid
synovial fluid. Biochem Biophys Res Commun 1980; 96: synovial $1449-54$.

30 Lunec J, Blake D R, McCleary S J, Brailsford S, Bacon P A. Self-perpetuating mechanisms of immunoglobulin $\mathbf{G}$ aggregation in rheumatoid inflammation. $\mathcal{F}$ Clin Invest 1985; 76: 2084-90.

31 Lunec J, Blake D R. Determination of dehydroascorbic acid and ascorbic acid in serum and synovial fluid of patients with rheumatoid arthritis. Free Radical Research Communications 1986; 1: 31-41.

32 Lund-Oleson K. Oxygen tension in synovial fluids. Arthritis Rheum 1970; 13: 769-76.

33 Edwards S W, Hallet M B, Campbell A K. Oxygen radical production may be limited by oxygen concentration. Biochem $\mathcal{F}$ 1984; 217: 851-4.

34 Falchuk K H, Goetzl E J, Kulka J P. Respiratory gases of synovial fluids. An approach to synovial tissue circulatorysynovial fluids. An approach to synovial tissue circulatory-
metabolic imbalance in rheumatoid arthritis. Am $₹$ Med metabolic imbalance

35 Jayson M I V, Dixon A St J. Intra-articular pressures in rheumatoid arthritis of the knee. I. Pressure changes during passive joint distension. Ann Rheum Dis 1970; 29: 261-5.

36 Merry P, Winyard P G, Morris C J, Grootveld M, Blake D R. Oxygen free radicals, inflammation, and synovitis: the current status. Ann Rheum Dis 1989; 48: 864-70.

37 Woodruff T, Blake D R, Freeman J, Andrews F J, Salt P, Lunec J. Is chronic synovitis an example of reperfusion injury? Ann Rheum Dis 1986; 45: 608-11.

38 Grootveld M C, Henderson E B, Farrell A, Blake D R, Parkes H G, Haycock P. Oxidative damage to hyaluronate and glucose in synovial fluid during exercise of the inflamed and glucose in synovial fluid during exercise of the inflamed joint: detection of abnormal low molecular weight metabolites by proton nuclear mag

39 Grootveld M C, Henderson E B, Farrell A, Blake D R. $A$ proton nuclear magnetic resonance investigation of oxidative damage to hyaluronate and glucose in synovial fluid during exercise of the inflamed rheumatoid joint. $\mathrm{BrF}$ Rhewoutol 1990; 29: (suppl 1): 97

40 Blake D R, Merry P, Unsworth J, et al. Hypoxic-reperfusion injury in the inflamed joint. Lancet 1989; i: 289-93.

41 Laurent T C. Biochemistry of hyaluronan. Acta Otolaryngol Suppl (Stockh) 1987; 442: 7-24.

42 Underhill C B, Thurn A L, Lacey B E. Characterization and identification of the hyaluronate binding site from membranes of 3T3 cells. F Biol Chem 1985; 260: 8128-33.

43 Green S J, Tarone G, Underhill C B. Distribution of hyaluronate and hyaluronate receptors in the adult lung. $\mathcal{F}$ hell Sci 1987; 89: 145-56.

44 Underhill C B, Green S J, Cologlio P M, Tarone G. The hyaluronate receptor is identical to a glycoprotein of 85,000 Mr (gp 85) as shown by a monoclonal antibody that Mr (gp 85) as shown by a monocional antibody that interferes

45 Lacey B E, Underhill C B. The hyaluronate receptor is associated with actin filaments. $\mathcal{F}$ Cell Biol 1987; 105: $1395-404$.

46 Underhill C B, Chi-Rosso G, Toole B P. Effects of detergent solubilization on the hyaluronate binding site from mem- branes of Simian virus transformed 3T3 cells. $\mathcal{F}$ Biol Chem 1983; 258: 8086-91.

47 Underhill C B. The interaction of hyaluronate with the cell surface: the hyaluronate receptor and the core protein. In: Evered D, Whelan J, eds. The biology of hyaluronan. Chichester: Wiley, 1989: 87-106. (Ciba Foundation Symposium, No 143.)

48 Goldberg $R$ L, Toole B P. Hyaluronate inhibition of cell proliferation. Arthritis Rheum 1987; 30: 769-78.

49 Balazs E A, Darzynkiewicz Z. The effect of hyaluronic acid on fibroblasts, mononuclear phagocytes and lymphocytes. on fibroblasts, mononuclear phagocytes and lymphocytes. In: Kulanen E, Pikkarainen J, eds. The biolo

50 Annastassiades T, Robertson W. Modulation of mitogendependent lymphocyte stimulation of hyaluronic acid. $\mathcal{f}$ Rheumatol 1984; 11: 729-34.

51 Forrester J V, Balazs E A. Inhibition of phagocytosis by high molecular weight hyaluronate. Immunology 1980; 40: 435-46.

52 Ahlgren T, Jarstrand C. Hyaluronic acid enhances phagocytosis of human monocytes in vitro. F Clin Immunol 1984; 4: 246-9.

53 West D C, Hampson I N, Arnold F, Kumar S. Angiogenesis induced by degradation products of hyaluronic acid. Science 1985; 228: $1324-6$.

54 Punzi L, Schiavon F, Cavasin F, Ramonda R, Gambari P F, Todesco $S$. The influence of intra-articular hyaluronic acid on PGE ${ }_{2}$ and cAMP of synovial fluid. Clin Exp Rheumatol on $\mathrm{PGE}_{2}$ and $\mathrm{CAMP}$

55 Ellenhorn M J, Barceloux D G. Medical toxicology: diagnosis and treatment of human poisoning. New York: Elsevier, 1988: 801-5.

56 McMartin K E, Ambre J J, Tephly T R. Methanol poisoning: role for formic acid accumulation in the metabolic acidosis. Am F Med 1980; 68: 414-8.

57 Martin-Amat G, McMartin K E, Hayreh S S, Tephly T R. Methanol poisoning: occular toxicity produced by formate. Toxicol Appl Pharmacol 1978; 45: 201-8.

58 Peyron J G, Balazs E A. Preliminary clinical assessment of sodium hyaluronate injection into human arthritic joints. Pathol Biol (Paris) 1974; 22: 731-6.

59 Weiss C, Balazs E A, St Onge R, Denlinger J L. Clinical studies of the intra-articular injection of Healon (sodium hyaluronate) in the treatment of osteoarthritis of human hyaluronate) in the treatment of osteoarthritis of human knees. In: Talbot J H, ed. Seminars in arthritis and rheuma $143-4$.

60 Namiki O, Toyoshima H, Morisaki N. Therapeutic effect of intra-articular injection of high molecular weight hyaluronic acid on osteoarthritis of the knee. International foumal of Clinical Pharmacology and Biopharmacology 1982; 20: 501-7.

61 Solomon L, Helfet A J. Osteoarthritis. In: Helfet A J, ed. Disorders of the knee. 2nd ed. Philadelphia: Lippincott, 1982: 183-98.

62 Schichikawa K, Maeda A, Ogawa N. Evaluation of drug effectiveness of sodium hyaluronate for osteoarthritis deformans of the knee. Rheumatism 1983; 23: 280-90.

63 Leardini G, Franceschini M, Mattara L, Bruno R, Perbellini A. Intra-articular sodium hyaluronate (Hyalgan) in gonarthritis. A controlled study comparing methyl prednisolone arthritis. A controlled study comparing methyl prednit

64 Punzi L. Schiavon F, Ramonda R, Malatests V, Gambari P F, Todesco S. Intra-articular hyaluronic acid in the $P$ F, Todesco S. Intra-articular hyaluronic acid in the treatment of inflammatory and non-inflammatory knee

65 Dixon St I, Jacoby R K, Berry H, Hamilton E B D. Clinical Dixon St J, Jacoby R K, Berry H, Hamilton E B D. Clinical
trial of intra-articular injection of sodium hyaluronate in patients with osteoarthritis of the knee. Curr Med Res Opin 1988; 11: 205-13. 